\title{
Seeded Porous Silicon Preparation as a Substrate in the Growth of $\mathrm{ZnO}$ Nanostructures
}

\author{
Kevin Alvin Eswar ${ }^{1,2,3, a^{*}, \text { Ajis Lepit }}{ }^{2, b}$, Rosfayanti Rasmidi ${ }^{2, c}$, \\ Husairi Fadzilah Shuhaimi ${ }^{1,3, \mathrm{~d}}$, Nurul Afaah Abdullah ${ }^{1,3, \mathrm{e}}$, \\ Noor Aadilla Abdul Aziz 1, 3, f , Nur Amierah Mohd Asib ${ }^{1,3,9}$, Azlinda Aziz 1, 2, 3, h, \\ Zuraida Khusaimi $^{1,3, i}$, Salman A.H. Alrokayan ${ }^{5, j}$, Haseeb A. Khan ${ }^{5, k}$, \\ Mohamad Rusop ${ }^{1,4,1}$, Saifollah Abdullah ${ }^{1,3, m}$ \\ ${ }^{1}$ NANO-SciTech Centre (NST), Institute of Science, Universiti Teknologi MARA (UiTM), \\ 40450 Shah Alam, Selangor, Malaysia \\ ${ }^{2}$ Faculty of Applied Sciences, Universiti Teknologi MARA (UiTM), Cawangan Kota Kinabalu, \\ Sabah, Malaysia \\ ${ }^{3}$ Faculty of Applied Sciences, Universiti Teknologi MARA (UiTM), \\ 40450 Shah Alam, Selangor, Malaysia \\ ${ }^{4}$ NANO-Electronic Centre (NET), Faculty of Electrical Engineering, Universiti Teknologi MARA \\ (UiTM), 40450 Shah Alam, Selangor, Malaysia \\ ${ }^{5}$ Department of Biochemistry, College of Science, King Saud University (KSU), Riyadh 11451, \\ Kingdom of Saudi Arabia

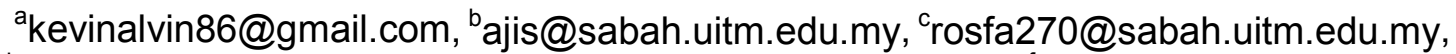
dmhusairifadzilah@yahoo.com, ${ }^{e}$ afaahabdullah@yahoo.com, ${ }^{f}$ aadilaazizali@gmail.com, gamierahasib@yahoo.com, hazlindazz@gmail.com, 'zuraidakhusaimi@gmail.com, 'haseeb@ksu.edu.sa, kdr.salman@ksu.edu.sa 'rusop@salam.uitm.edu.my, msaifollah@salam.uitm.edu.my
}

Keywords: Porous Silicon, $\mathrm{ZnO}$ nanostructures, electrochemical etching, sol-gel, hydrothermal immersion, annealing temperature

\begin{abstract}
In this work, seeded porous silicon (PSi) was used as a substrate in the growth of $\mathrm{ZnO}$ nanostructures. PSi was prepared by electrochemical etching method. $\mathrm{ZnO}$ thin films as seeded were deposited via sol-gel spin coating method. $\mathrm{ZnO}$ nanostructures were grown on seeded PSi using hydrothermal immersion method. In order to study the effect of post-heat treatment on the substrate, post annealing temperature were varied in the range of 300 to $700{ }^{\circ} \mathrm{C}$. The FESEM results shows $\mathrm{ZnO}$ thin film composed of nanoparticles were distributed over the PSi surface. Based on AFM characterization, the smoothest surface was produced at post annealing temperature of 500 ${ }^{\circ} \mathrm{C}$. There are two different peaks appeared in PL characterization. The peak in near-UV range is belonging to $\mathrm{ZnO}$ thin films while a broad peak in visible range can be attributed to $\mathrm{ZnO}$ defects and PSi surface. In addition, FESEM, XRD and PL were used to characterize the $\mathrm{ZnO}$ nanostructures. The FESEM results revealed $\mathrm{ZnO}$ nano-flower were successfully grown on seeded PSi. Hexagonal wurtzite of $\mathrm{ZnO}$ with dominated by the plane (100), (002), and (101) was found by XRD characterization. Two different peaks in UV range and visible range can be attributed to $\mathrm{ZnO}$ nano-flower and various defects of $\mathrm{ZnO}$, respectively.
\end{abstract}

\section{Introduction}

Special characteristic of a wide band gap of $3.37 \mathrm{eV}$ and a large binding energy of $60 \mathrm{meV}$ make $\mathrm{ZnO}$ semiconductor become a potential material in optoelectronic device applications. $\mathrm{ZnO}$ nanostructures doped by Aluminum were studied by Mamat et al. for ultraviolet photoconductive sensors [1]. Baek et al. have studied hybrid silicon wire and planar solar cells for solar cell application as a potential renewable energy source [2]. In addition, Kim et al. have proposed that the photoluminescence (PL) properties of $\mathrm{ZnO}$ nanostructures grown on PSi can be applied to white 
light emitting devices [3]. Several methods have been used to produce $\mathrm{ZnO}$ nanostructures including radio frequency (RF) magnetron sputtering, pulsed laser deposition, chemical vapour deposition, atomic layer deposition, sol-gel deposition and hydrothermal immersion deposition [410]. Among them, hydrothermal immersion method was very popular due to simplicity, low cost and can be conducted in low-temperature. Self-assembly deposition such as hydrothermal immersion method need a nucleation site called seed layer or catalyst to produce high crystalline quality nanostructures [11]. In this work, $\mathrm{ZnO}$ thin films were deposited on PSi using spin coating method. Then, the $\mathrm{ZnO}$ nanostructures were grown on seeded PSi via hydrothermal immersion method.

\section{Experimental}

P-type silicon was cleaned using acetone, methanol and diluted hydrofluoric acid (HF) before being etched via electrochemical etching [12]. A mixture of HF $48 \%$ and absolute ethanol was used as an electrolyte. The etching process was assisted by current densities of $20 \mathrm{~mA} / \mathrm{cm}^{2}$ and potential difference of $100 \mathrm{~V}$ for 20 minutes. In order to prepare $\mathrm{ZnO}$ thin film as a seed layer on PSi, sol-gel spin coating was employed. Zinc acetate dihydrate, diethanolamine, and isopropyl were used as starting material, stabilizer and solvent, respectively. The rotation per minute (rpm) of spincoater was maintained at 300 in $60 \mathrm{~s}$ [13]. The seeded PSi was treated in various annealing temperature in the range of 300 to $700{ }^{\circ} \mathrm{C}$. Then, the sample was characterized using field emission scanning electron microscopy (FESEM), atomic force microscopy (AFM), and photoluminescence (PL) spectroscopy. ZnO nanostructures were grown on the selected seeded PSi substrate via hydrothermal immersion method. Zinc nitrate hexahydrate, hexamethylenetetramine (HMTA), and deionized water were used as a starting material, stabilizer and solvent respectively [14]. The surface morphology and the crystallinty were studied using FESEM, and X-ray diffraction (XRD) spectroscopy, respectively. The optical property was investigated using PL spectroscopy.

\section{Result and discussion}

Fig. 1 shows the FESEM and AFM images of seeded PSi that treated in different postannealing temperatures. Based on the figure, the seeded PSi was composed by ZnO nanoparticles. The particle size of $24.7 \mathrm{~nm}$ increased to $25.6 \mathrm{~nm}$ when the annealing temperature was increased from $300{ }^{\circ} \mathrm{C}$ to $400{ }^{\circ} \mathrm{C}$. This phenomena has also been observed by other researcher [15]. It can be explained by thermal expansion where the kinetic energy of an atom increases due to the increase of post-annealing temperatures. However, the average particle size decreased to $21.4 \mathrm{~nm}$ at annealing temperature of $500{ }^{\circ} \mathrm{C}$. This can be explained by the re-arrangement of atom within the $\mathrm{ZnO}$ nanoparticles. The atom has sufficient thermal energy and can move to any space within the particle and crystalline arrangement. Therefore, the size of the particle decreases due to the ability to fill the space within the crystalline structure. It is believed that the crystalline quality has also increased because the atom will move to the most favourable position [16]. Furthermore, the atoms will move to adjacent particles at $600^{\circ} \mathrm{C}$ and $700{ }^{\circ} \mathrm{C}$, therefore, they will merges together and subsequently form a larger particle. In addition, the increases of the annealing temperature were increased the thermal energy including the particle surface energy [17]. So, it was merged to adjacent particles to minimize the surface energy. The average surface roughness of seeded PSi was analysed by using AFM characterization instrument. The average surface roughness of $\mathrm{ZnO}$ thin film surface is 1.51 $\mathrm{nm}$ at annealing temperature of $300{ }^{\circ} \mathrm{C}$ and increases to $1.64 \mathrm{~nm}$ at $400{ }^{\circ} \mathrm{C}$. However, the average surface roughness decreases to $1.47 \mathrm{~nm}$ at $500{ }^{\circ} \mathrm{C}$. Then it becomes rougher once more when increasing the annealing temperatures. The average surface roughness of nanostructured film is increased at $400{ }^{\circ} \mathrm{C}$ due to non-uniformity of $\mathrm{ZnO}$ nanoparticles size. At annealing temperature of $500{ }^{\circ} \mathrm{C}$, the crystalline quality increases due to the atom arrangements being in favourable position and therefore making the average surface roughness decrease [18]. Besides, the size of $\mathrm{ZnO}$ nanoparticles was more uniform at this annealing temperature as seen in FESEM images. The 
average surface roughness increases when the post-annealing temperature was increased from 500 ${ }^{\circ} \mathrm{C}$ to $600{ }^{\circ} \mathrm{C}$. This may be attributed to the non-uniform in the increases of $\mathrm{ZnO}$ nanoparticles size. The same phenomenon was also seen when the post-annealing temperature increased to $700{ }^{\circ} \mathrm{C}$. As discussed before, the increment of $\mathrm{ZnO}$ nanoparticles may be related to the increases of its surface energy. It tends to merge with its adjacent particles to reduce the surface energy [19]. The nonuniform $\mathrm{ZnO}$ particles sizes contribute high average surface roughness.
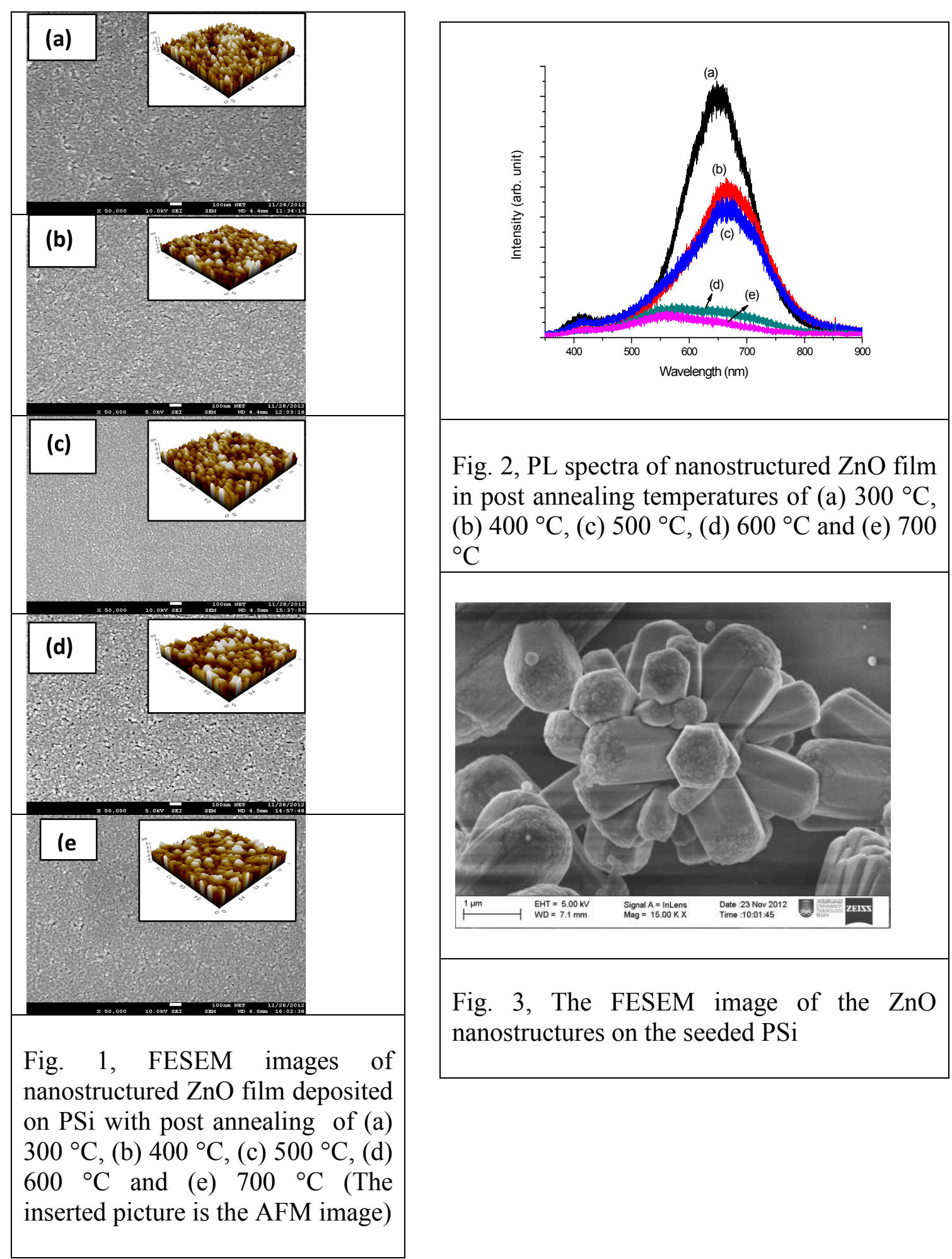

Fig. 2, PL spectra of nanostructured $\mathrm{ZnO}$ film in post annealing temperatures of (a) $300{ }^{\circ} \mathrm{C}$, (b) $400{ }^{\circ} \mathrm{C}$, (c) $500{ }^{\circ} \mathrm{C}$, (d) $600{ }^{\circ} \mathrm{C}$ and (e) 700 ${ }^{\circ} \mathrm{C}$

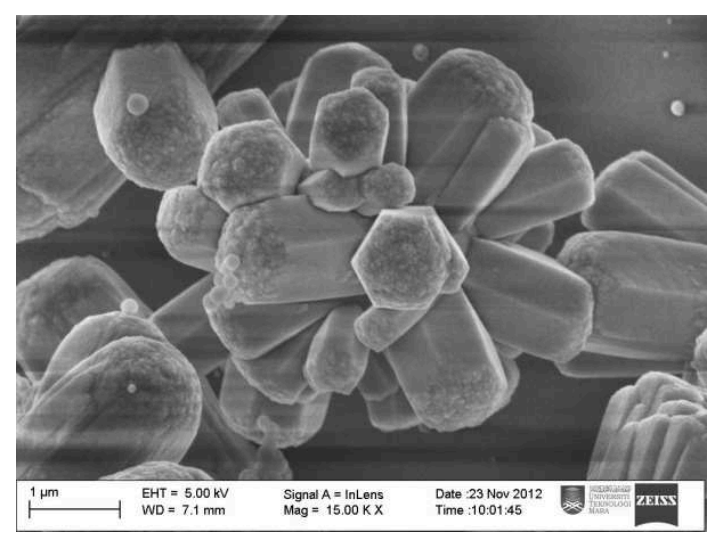

Fig. 3, The FESEM image of the $\mathrm{ZnO}$ nanostructures on the seeded PSi 


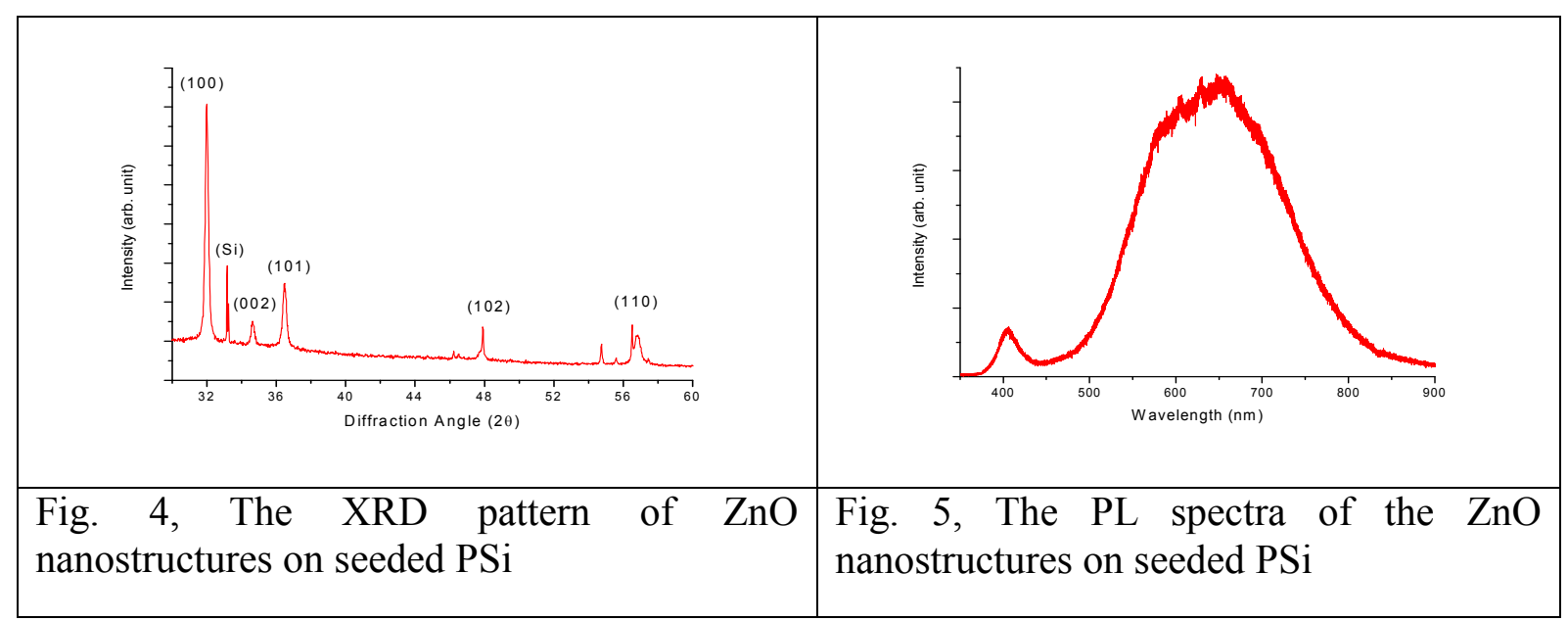

Fig. 2 shows the PL spectra of the seeded PSi in the range of $350 \mathrm{~nm}$ to $900 \mathrm{~nm}$. In general, the findings show three distinct peaks at UV-blue region, green-yellow region and red region. The first peak, in UV-blue region is relates specifically to the $\mathrm{ZnO}$ nanoparticles; the second peak in green-yellow region is relevant to the defects of nanostructured $\mathrm{ZnO}$ film; and the third peak, within the red is due to the PSi surface [20]. Fig. 3 shows the FESEM images of the ZnO nanostructures on the seeded PSi template. Based on the figure, it was produced flower-like structures of $\mathrm{ZnO}$. The petals were composed of $\mathrm{ZnO}$ nanorod with $\mathrm{ZnO}$ nanoparticles still can be seen on the top of it. XRD spectrometer was used to study the structural properties of $\mathrm{ZnO}$ nanostructures. Fig. 4 shows the XRD pattern of the ZnO nanostructures on seeded PSi. As can be seen, several diffraction peaks were observed in the range of $30^{\circ}$ to $60^{\circ}$. It can be attributed to the presence of $\mathrm{ZnO}$ nanostructures and seeded PSi template. Peak of (100), (002), (101), (102) and (110) correspond to hexagonal ZnO wurtzite can be observed apparently (JCPDS No: 36-1451). Besides, peak of impurity corresponds to silicon was also appeared in between of plane (100) and (002), located at $\sim 33.2^{\circ}$ for all samples (JCPDS No: 17-0901) [21, 22]. Fig. 5 shows the PL spectra of ZnO nanostructures on seeded PSi in the range of $350 \mathrm{~nm}$ to $900 \mathrm{~nm}$. As can be seen, two distinct peaks are appeared where low emission peak intensity located within UV region and high intensity within the visible region. In the UV region, it can be attributed to the intrinsic property of the wurtzite $\mathrm{ZnO}$ and excitonic recombination $[23,24]$. On the other hand, the visible region can be ascribed to the radial recombination of photogenerated holes with single ionized charge states of specific defects, such as oxygen vacancies or zinc interstitials [25-27].

\section{Conclusion}

As a conclusion, the result revealed that the temperature is highly influenced the formation of $\mathrm{ZnO}$ thin films. Then, the $\mathrm{ZnO}$ nano-flower was successfully grown on seeded PSi. The XRD result shows the formation of hexagonal $\mathrm{ZnO}$ wurtzite. In PL spectra, two peaks are appeared in UV and visible region. It can be attributed to the excitonic recombination in the UV region and $\mathrm{ZnO}$ defects in the visible region.

\section{Acknowledgement}

We would like to express our gratitude to Ministry of Education Malaysia, Research Grant from the Ministry of Science, Technology and Innovation of Malaysia. This work was supported by the LongTerm Research Grant Scheme for Nanostructures, Nanomaterials and Devices for Fuel Cells and Hydrogen Production (600-RMI/LRGS 5/3 (3/2013)) and Research Management Institute (RMI), Universiti Teknologi MARA (UiTM), Malaysia for their support. The authors would also like to acknowledge the Department of Biochemistry, College of Science, King Saud University, Kingdom of Saudi Arabia for the Research Collaboration and Support. 


\section{References}

[1] Mamat M.H., Khusaimi Z., Zahidi M.M., and Mahmood M.R. Performance of an Ultraviolet Photoconductive Sensor Using Well-Aligned Aluminium-Doped Zinc-Oxide Nanorod Arrays Annealed in an Air and Oxygen Environment, Japanese Journal of Applied Physics, 50 (6) (2011) 06GF05.

[2] Baek S.-H., Kim S.-B., Shin J.-K., and Hyun Kim J. Preparation of hybrid silicon wire and planar solar cells having $\mathrm{ZnO}$ antireflection coating by all-solution processes, Solar Energy Materials and Solar Cells, 96 (2012) 251-256.

[3] Kim M.S., Yim K.G., Kim S., Nam G., and Leem J.-Y. White light emission from nanofibrous $\mathrm{ZnO}$ thin films/porous silicon nanocomposite, Journal of Sol-Gel Science and Technology, 59 (2) (2011) 364-370.

[4] Rouhi J., Alimanesh M., Mahmud S., Dalvand R.A., Raymond Ooi C.H., and Rusop M. A novel method for synthesis of well-aligned hexagonal cone-shaped $\mathrm{ZnO}$ nanostructures in field emission applications, Materials Letters, 125 (0) (2014) 147-150.

[5] Rouhi J., Alimanesh M., Dalvand R., Ooi C.H.R., Mahmud S., and Mahmood M.R. Optical properties of well-aligned $\mathrm{ZnO}$ nanostructure arrays synthesized by an electric field-assisted aqueous solution method, Ceramics International, 40 (7, Part B) (2014) 11193-11198.

[6] Rouhi J., Mahmud S., Naderi N., Ooi C.R., and Mahmood M.R. Physical properties of fish gelatin-based bio-nanocomposite films incorporated with $\mathrm{ZnO}$ nanorods, Nanoscale Research Letters, 8 (1) (2013) 1-6.

[7] Cui L., Zhang H.-Y., Wang G.-G., Yang F.-X., Kuang X.-P., Sun R., and Han J.-C. Effect of annealing temperature and annealing atmosphere on the structure and optical properties of $\mathrm{ZnO}$ thin films on sapphire (0001) substrates by magnetron sputtering, Applied Surface Science, 258 (7) (2012) 2479-2485.

[8] Lan S.M., Uen W.Y., Chan C.E., Chang K.J., Hung S.C., Li Z.Y., Yang T.N., Chiang C.C., Huang P.J., Yang M.D., Chi G.C., and Chang C.Y. Morphology and optical properties of zinc oxide thin films grown on $\mathrm{Si}$ (100) by metal-organic chemical vapor deposition, Journal of Materials Science: Materials in Electronics, 20 (S1) (2008) 441-445.

[9] Eswar K.A., Rouhi J., Husairi F.S., Dalvand R., Alrokayan S.A.H., Khan H.A., Rusop Mahmood M., and Abdullah S. Hydrothermal growth of flower-like ZnO nanostructures on porous silicon substrate, Journal of Molecular Structure, 1074 (0) (2014) 140-143.

[10] Eswar K.A., Azlinda A., Husairi F.S., Rusop M., and Abdullah S. Post Annealing Effect on Thin Film Composed ZnO Nano-particles on Porous Silicon, Nano Bulletin, 2 (2) (2013) 130212(1-6)

[11] Ko Y.H., Leem J.W., and Yu J.S. Controllable synthesis of periodic flower-like ZnO nanostructures on Si subwavelength grating structures, Nanotechnology, 22 (20) (2011) 205604.

[12] Eswar K., Azlinda A.A., Husairi F., Rusop M., and Abdullah S. Synthesis of ZnO Thin Film on Porous Silicon by Spin Coating in Various Low Molarities Precursor, Advanced Materials Research, 701 (2013) 167-171.

[13] Eswar K.A., Ab Aziz A., Rusop Mahmood M., and Abdullah S. Surface Morphology of Seeded Nanostructured $\mathrm{ZnO}$ on Silicon by Sol-Gel Technique, Advanced Materials Research, 667 (2013) 265-271.

[14] Eswar K.A., Husairi H.F., Rusop M., and Abdullah S. ZnO nanostructures on different silicon-based substrate via simple sol-gel immersion method, Int. J. Microstructure and Materials Properties, 8 (6) (2013) 478-487.

[15] Varnamkhasti M.G., Fallah H.R., and Zadsar M. Effect of heat treatment on characteristics of nanocrystalline $\mathrm{ZnO}$ films by electron beam evaporation, Vacuum, 86 (7) (2012) 871875. 
[16] Min S.K., Kwang G.Y., Jae-Young L., Soaram K., Giwoong N., Dong-Yul L., Jin S.K., and Jong S.K. Effects of Annealing Temperature on the Structural and the Optical Properties of $\mathrm{ZnO}$ Thin Films Grown on Porous Silicon by Using Plasma-assisted Molecular Beam Epitaxy, Journal of the Korean Physical Society, 59 (3) (2011) 2343.

[17] Callister W.D., Material Science And Engineering: An Introduction, 7th ed.: John Wiley and Son (Asia) Pte. Ltd, 2007.

[18] Eswar K.A., Rouhi J., Husairi H.F., Rusop M., and Abdullah S. Annealing Heat Treatment of ZnO Nanoparticles Grown on Porous Si Substrate Using Spin-Coating Method, Advances in Materials Science and Engineering, 2014 (2014) 6.

[19] Neouze M.-A. Nanoparticle assemblies: main synthesis pathways and brief overview on some important applications, Journal of Materials Science, 48 (21) (2013) 7321-7349.

[20] Huang X.L., Ma S.Y., Ma L.G., Bian H.Q., and Su C. Microstructure and optical properties of $\mathrm{ZnO}$ /porous silicon nanocomposite films, Physica E: Low-dimensional Systems and Nanostructures, 44 (1) (2011) 190-195.

[21] Min S.K., Kwang G.Y., Jae-Young L., Soaram K., Giwoong N., Do Y.K., Sung-O K., Dong-Yul L., Jin S.K., and Jong S.K. Nanocrystalline ZnO Thin Films Grown on Porous Silicon by Sol-gel Method and Effects of Post-annealing, Journal of the Korean Physical Society, 59 (2) (2011) 346.

[22] Hsu H.C., Cheng C.S., Chang C.C., Yang S., Chang C.S., and Hsieh W.F. Orientationenhanced growth and optical properties of $\mathrm{ZnO}$ nanowires grown on porous silicon substrates, Nanotechnology, 16 (2) (2005) 297-301.

[23] Abdulgafour H., Yam F., Hassan Z., Al-Heuseen K., and Jawad M. ZnO nanocoral reef grown on porous silicon substrates without catalyst, Journal of Alloys and Compounds, 509 (18) (2011) 5627-5630.

[24] Gao X., Li X., and $\mathrm{Yu} \mathrm{W}$. Flowerlike $\mathrm{ZnO}$ nanostructures via hexamethylenetetramineassisted thermolysis of zinc-ethylenediamine complex, The Journal of Physical Chemistry B, 109 (3) (2005) 1155-1161.

[25] Egelhaaf H.-J. and Oelkrug D. Luminescence and nonradiative deactivation of excited states involving oxygen defect centers in polycrystalline $\mathrm{ZnO}$, Journal of crystal growth, 161 (1) (1996) 190-194.

[26] Vanheusden K., Warren W., Seager C., Tallant D., Voigt J., and Gnade B. Mechanisms behind green photoluminescence in $\mathrm{ZnO}$ phosphor powders, Journal of Applied Physics, 79 (10) (1996) 7983-7990.

[27] Aguilar C.A., Haight R., Mavrokefalos A., Korgel B.A., and Chen S. Probing electronic properties of molecular engineered zinc oxide nanowires with photoelectron spectroscopy, ACS nano, 3 (10) (2009) 3057-3062. 